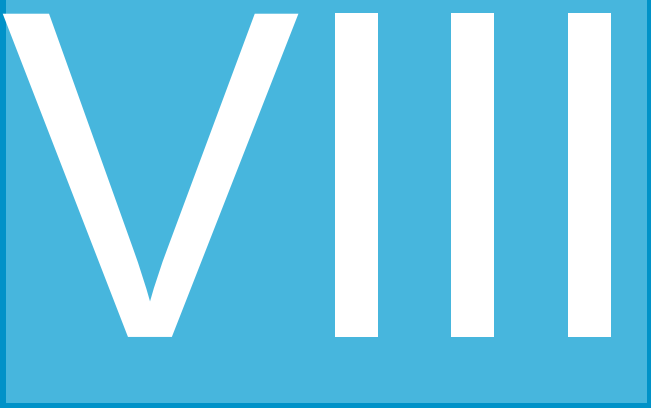

\title{
Los valores como resultado de la relación Dios-hombre y conducta empresarial
}

\section{Values as a result of the God-man and business conduct Universidad Peruana Unión, Perú}

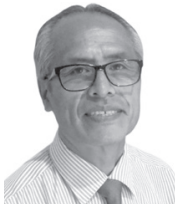

\section{Edual Delmar Santos Gutierrez}

Doctor en Ciencias Empresariales-UNED Costa Rica. Master en Teología Pastoral-Universidad Adventista de Centroamérica-Costa Rica. Master en Administración de Negocios-Suthern Adventist University, USA. Master en Contabilidad con mención en Auditoria (Universidad Inca Garcilazo de la Vega, Perú. Contador Público, Universidad Nacional Hermilio Valdizan-Huánuco. Administrador de Empresas - Universidad Adventista de Centroamérica, Costa Rica. Coordinador Facultad de Ciencias Empresariales-UPeU filial Tarapoto. Docente Universitario en UPeU (Perú), Universidad Adventista de Colombia (Colombia), Universidad Adventista de Bolivia (Bolivia) y Universidad Adventista de Centroamérica (Costa Rica). Expositor de temas profesionales y de motivación en varios países de Indo América. Autor de 7 libros, el último por editorial IDEAS: Si eres pobre no culpes a Dios 


\section{Resumen}

El objetivo de esta revisión es destacar la importancia de los valores que se construyen como resultado de la relación entre Dios y el hombre. Los valores son experiencias que provienen de múltiples fuentes, y pueden ser objetivas o subjetivas. Esto crea una corriente social opresiva de valores dominantes, aceptados por exigencia cultural con los cuales uno podría no estar identificado. Los valores experimentados bajo el dominio del individualismo deconstruyen la civilización, porque el ser humano no es autónomo ni solitario. Su razón de ser es la comunidad. La conducta empresarial supervive en sociedad, por tanto, se requiere vínculos fuertes y estos únicamente se encuentran en la relación Dios-hombre.

Palabras clave: Valores, deconstrucción, relación con Dios, conducta empresarial.

\section{Abstract}

The goal of this review is to highlight the importance of the values that are built as a result of the relationship between God and man. Values are experiences that come from multiple sources, and can be objectives and subjectives. This creates an oppressive social thought of dominant values, accepted by the cultural demand with which one could not be identified. The experienced values under the domination of individualism deconstructed the civilization, because the human being is not autonomous or a lonely creation. His being reason is the community. The business behavior survives in the society, therefore requires strong links and these are only found in the man's relationship with God.

Keywords: Values, deconstruction, relationship with God, business behavior. 


\section{Introducción}

El objetivo de esta revisión es destacar la importancia de los valores que construyen civilización como resultado de un vínculo fuerte en la relación Dios-Hombre. Los valores son experiencia provenientes de múltiples fuentes, cuyo límite esta inconcluso, se expande como el cosmos en un (des) orden de complejidad, desconocido al orden y organización del imaginario colectivo de la humanidad. Son expresiones objetivas para uno y subjetivas para otros, pero se observa un claro dominio de la subjetividad, por tanto los valores toman la forma del individuo que valora, limitado solamente por los valores del "otro" que es un ocasional acompañante de la vida. Esto crea una corriente social opresiva de valores dominantes, aceptados por exigencia cultural con los cuales uno no está identificado pero por los signos de los tiempos, que es la tolerancia, se acepta a pesar de estar en desacuerdo.

\section{Valor como cuantía y como moral}

Es de percepción general, incluso de los que son incapaces de conceptualizar la palabra valor, que este es la trama y urdimbre de la estructura de la vida social e individual, tanto de las naciones como del universo inconcluso.

Valor, como cuantía, expresa la esencia de las relaciones económicas y sin ellas se destruye el edificio del cálculo especulativo y también cualquier teorización social en beneficio de la masa y poniendo fin a la concepción moderna de nación y globalización. Aunque valor es diferente en el neocapitalismo supérstite, del concepto sobre el mismo en el diluido socialismo o comunismo utópico.

La cuantía objetiviza un precio-valor que puede sacrificar uno por un bien que vale solo en la subjetividad del individuo, pues seguirá siendo una cuantía numérica equivalente a un valor simbólico cuya asignación exterioriza los cimientos metafísicos de los escondrijos del alma y que se socializa por la expectativa de grupo jaloneado por el sujeto nervioso más que por la inteligencia advertida de las manipulaciones sudoríparas que movilizan al individuo o a la especie.

Como cuantía el valor expresa los límites al que puede aspirar un comprador y el límite en donde debe detenerse un vendedor, el valor justo de mercado o de la mano invisible1. No existe mayor creatividad en esto, a

\footnotetext{
${ }^{1}$ Mano invisible es la nominación que Adam Smith nombra al mercado como regulador de precios en "La riqueza de las naciones" 
menos que sea violentada por el monopolio y/o oligopolio camuflado en las leyes democráticas que determinan cuantías sin respetar los límites del consumidor.

Eso hace de la cuantía "un valor que vale para los valores morales", ahí reside la raíz de la cuantía. Uno puede fijar indebidamente una alta cuantía guiado por su ambición egoísta o baja cuantía por su generosidad o cuantía media, guiado por sus criterios de justicia y equidad.

Egoísmo, generosidad y justicia, son valores humanos y morales objetivizados en la cuantía. Como valores humanos son intangibles o metafísicos por no decir invisibles o espiritual para los otros. Al traducirse en cuantía se torna tangible o físico por no decir material y por tanto mundano. Esto es inherente el ser humano en tanto sujeto de elecciones constantes, las elecciones están guiadas por valores y valorizaciones en un círculo virtuoso o vicioso entre la física y la metafísica o a la inversa, dependiendo de la cosmovisión materialista o teísta que el sujeto hermeneuta contenga en sus premisas subyacentes.

De esto se deriva que el humano es el valor encarnado y el valor es el humano sublimado, en la misma relación que la ecuación einsteniana de que "la materia es la energía concentrada y la energía es la materia diluida" ¿Cuál es el punto de encuentro entre lo metafísico y lo físico en el tema de encarnaciónsublimación? Los vanos intentos de la ciencia han dado resultados evasivos a esta correspondencia unívoca, empeorado por las consignas positivistas de que solo lo mesurable es científico y que solo el laboratorio prueba la existencia.

Esto nos conduce a pensar que si el ser humano es el sujeto pasivo de la razón de la creación y amo de la naturaleza, entonces su accionar frente al cosmos es acicateado por los valores, valores que configuran su existencia con tan solo respirar, deja de respirar y los valores dejan de ser porque los valores inherentes son solo apreciados en la relación entre la especie. Aunque están, no se visibilizan en solitario.

Sin embargo, también hay que admitir que los valores son el termómetro humano para evaluar la entropía de la raza que si no se reinventa se autodestruirá por la dinámica interna de sus propios conflictos. Este es el quid de los valores a través de la historia, en sus muchas crisis cíclicas siempre ha resurgido una negentropía que ha diluido a las fuerzas adversas que corrompen todo a su paso.

Los imperios formados en la media luna oriental como Babilonia, Medo Persia, Grecia y Roma sucesivamente debilitaron sus valores antes de su ruina militar y política. El ama súa, ama kella y ama llulla, del imperio incaico fueron debilitados por la sorda guerra entre Huáscar y Atahualpa, preludio de la caída. Pero como humanidad, la entropía de una reino fue aliviado por la negentropía del reino conquistador hasta encontrar la plenitud de su homeostasis de nueva civilización. 
Sin embargo, nadie en su sano juicio quiere tangibilizar la entropía, de allí los esfuerzos de la ciencia por eternizar la vida de los seres humanos. Sin duda, hay valores mayores a otros y cuya jerarquización es también materializado por otros valores, los mismos que también categorizan analíticamente en un listado sin fin de valores por su naturaleza y también por su destino.

Entonces la importancia (¿relativa o absoluta?) de los valores se fundamenta en la necesidad de existencia del ecosistema y el ecosistema tiene leyes absolutas que no conviven con la relativización humana frecuentemente visibilizada en un estado cultural dionisiaco o hedonista como perfila el siglo XXI.

Los movimientos de LGBT son una expresión de la época en donde lo social quiere encuadrarse en lo natural. El ecosistema natural norma la dicotomía de hombre-mujer. Pero la construcción social de los LGTB insiste en la hibridez "in-hibrida", de una sexualidad que no crea vida, solo satisface un placer, y toda ley a su favor solo será para legitimar el placer específico de dicha construcción social. Probablemente este era el fundamento subyacente en la afirmación de que: "Los europeos se están muriendo... y los matrimonios gay no producen niños" (Putin, 2016).

Sea de una manera u otra, si no existe correspondencia del ecosistema natural con el ecosistema humano, es más probable que el humano esté terminando con el natural. La naturaleza solo revela la capacidad del ser humano para conservarla o destruirla, y esto también es dictado por los valores de cada ser humano o de cada colectividad. En este sentido, e históricamente demostrado, si como humanos globalmente se existirá aun por mucho tiempo, como colectividad localizada se afronta la extinción si los valores no reflejan la excelsitud de la raza humana. Por otro lado, la grandeza de las naciones ha sido signada por la fortaleza de los valores anclados a los deberes, no a los placeres.

\section{Expansión en (des) orden de valores}

Pero reconocer, cuales son aquellos valores que dan fortaleza a la nación y cuales la debilitan, afrontan un grave problema porque cada humano tiene los suyos y lo que aparentemente son iguales en su forma se diferencia en su contenido. Los valores iguales no tienen equivalencia en su contenido para los de arriba y los de abajo, tampoco para los de izquierda y derecha, menos para los adelantado versus los retrasados; el inteligente y el ignorante, el blanco y el negro, el mayor de edad y el menor, cada quien le da el contenido cosmovisivo de su existencia. Por otro lado la hermenéutica de un fenómeno dependerá de qué lado de la orilla se encuentre el intérprete, más si este tiene una mente sistémica que gusta ver de todos los lados antes de su veredicto.

Revista Apunt. Univ. VOLUMEN VI • NÚMERO 2 p. 125-145 
Agustín de Hipona (1977), cuenta, que a un pirata capturado, Alejandro preguntó: "¿Qué te parece tener el mar sometido al pillaje?". "Lo mismo que a ti - respondió - el tener el mundo entero. Solo que a mí, como trabajo con una ruin galera, me llaman bandido, y a ti, por hacerlo con toda una flota, te llaman emperador". Un mismo acto tiene valores diferentes según el opinante.

Un mismo sujeto, indefinido e individualista tienes numerosos valores y paradójicos inclusive, es una corriente de agua por cuyo liquido navegan valores, uno alejándose y otros aproximándose, sin agarrar siquiera unos pocos, al ser indefinido no entiende de donde viene y a donde va, ni menos lo que hace. Es el sujeto esponja, recibe y suelta sin control pero al menos acumula valores por poco tiempo.

Entramos a las corrientes filosóficas, más cerebrales por supuesto, pero no por eso menos ingeniosas para fluir valores enmarcados dentro de sus propios límites conceptuales o reflexivos, esclavizados por la palabra y sus significados, como sostenía Derrida (1930-2003). Las corrientes filosóficas son profusas, dado la fuente de su construcción, el único requisito es eructar una definición nueva o vieja pero enriquecida con nuevos constructos que asombran y llenan un vació de entelequias.

La filosofía, en un individuo, funciona como una cosmovisión, la manera de ver e interpretar las cosas en el mundo interior y exterior, y es una manera particular, de ningún modo transferible aunque si comunicable. Como reflexión o como estilo de vida, atan la profusión de valores que emergen de ella enraizado en el marco de su concepción original. Por ejemplo, se numerará siete escuelas filosóficas y sus tendencias (Bartolomé, Ferreriros, Fondevilla y Morilla, 1979):

1. La tendencia idealista o también neo-kantiana o neo-fitchteana, reduce el valor a pura categoría mental, o sea, es pura subjetividad, descansa en los rincones del alma individual.

2. La tendencia realista o fenomenológica, reconoce los valores como un "ser en si" diferente de las esencias categoriales, se perciben, no como una intuición intelectual sino como una intuición emotiva

3. La tendencia psicologísta, sostiene que los valores se apoyan en las inclinaciones y afectos del sujeto, por consiguiente los valores son relativos totalmente.

4. La tendencia sociológica considera a los valores como meros hechos sociales, que deben ser examinados con los otros hechos, también relativos.

5. La tendencia existencialista y liberal, considera que los valores son creados por la libertad, sin ninguna norma objetiva absoluta. La 
libertad del hombre es el valor supremo.

6. La tendencia metafísica y espiritualista considera a los valores como una revelación del Absoluto. Dios es la identidad del ser y del valor.

7. La tendencia neo-positivista, reduce los juicios de valor a meras expresiones subjetivas de las emociones.

Y puede seguirse enumerando más filosofías, inclusive aparte de las mencionada por Juan Pablo II en su encíclica Fe y Razón (Fides et Ratio) del 14 de Diciembre de 1998, como peligrosas para la fe. Esta selva de filosofías, genera una constelación nubosa de valores, por el conocimiento tan amplio y disperso que Heideger (1951) escribió: "Ninguna época ha sabido conquistar tantos y tan variados conocimientos sobre el hombre como la nuestra... Sin embargo, ninguna ha conocido al hombre tan poco como la nuestra. En ninguna época el hombre se ha hecho tan problemático como en la nuestra".

El hombre problemático, lo es por su escala de valores y por la multiplicidad de ellos que en la mayoría de veces son contradictorios y otros destructivos. Intentos de ordenar los valores sistematizándolo de acuerdo a su destino, ha permitido que estudiosos como Rokeach propusieran un conjunto de valores clasificados en instrumentales y finales

\section{Cuadro 1. Escala de valores}

\begin{tabular}{ll}
\hline \multicolumn{1}{c}{ Instrumentales (deontología) } & \multicolumn{1}{c}{ Finales (Teleología) } \\
\hline Afectuoso & Amistad verdadera \\
Alegre & Amor pleno \\
Ambicioso & Armonía interna \\
Autocontrolado & Felicidad \\
Capaz & Igualdad \\
Cortés & Libertad \\
Honrado & Placer \\
Independiente & Reconocimiento social \\
Imaginativo & Respeto de sí mismo \\
Intelectual & Sabiduría \\
Limpio & Salvación \\
Lógico & Seguridad familiar \\
Magnánimo & Seguridad nacional \\
Obediente & Sentido del cumplimiento \\
Responsable & Un mundo bello \\
Servicial & Una vida emocionante \\
Valiente & Una vida confortable \\
Tolerante & Un mundo en paz \\
\hline
\end{tabular}

Fuente: Rokeach (1973) 
Los valores deontológicos son valores intermedios cuyo ejercicio es con el objeto de alcanzar los valores finales, una correcta correspondencia entre los medios y los fines permite una eticidad ajustada a las buenas prácticas; la falta de correspondencia genera un pragmatismo utilitarista de consecuencias imprevisibles, a esta falta de relación biunívoca se traduce con la sentencia asignada a Maquiavelo que el "fin justifica los medios".

A esta propuesta de Rokeach, que de ningún modo es limitativo, también se encuentran las propuestas de las escuelas axiológicas principales como la neokantiana de Baden, la austriaca y de Praga, la existencialista, la fenomenológica y la realista, cada cual tiene su concepto de valor que fuerzan por homogenizar los conceptos de valor de sus principales actores, y esto continúa, según López de Llergo (2005), algunos pedagogos tienen sus posturas axiológicas y proponen valores categorialmente.

Cuadro 2. Valores propuestos

\begin{tabular}{|c|c|c|c|c|c|c|c|}
\hline $\begin{array}{l}\text { Peda } \\
\text { gogo }\end{array}$ & $\begin{array}{l}\text { Gonzales- } \\
\text { Simancas }\end{array}$ & Castillo & lenz & Debesse & $\begin{array}{l}\text { García } \\
\text { Hoz }\end{array}$ & $\begin{array}{l}\text { Marín } \\
\text { lbañez }\end{array}$ & F. Otero \\
\hline Valores & $\begin{array}{l}\text { Útiles } \\
\text { Vitales } \\
\text { Morales } \\
\text { Estéticos } \\
\text { Religiosos } \\
\text { Intelectuales }\end{array}$ & $\begin{array}{l}\text { Físicos } \\
\text { Económicos } \\
\text { Morales } \\
\text { Estéticos } \\
\text { Religiosos } \\
\text { Intelectu- } \\
\text { ales } \\
\text { Afectivos } \\
\text { Sociales }\end{array}$ & $\begin{array}{l}\text { Políticos } \\
\text { Teóricos } \\
\text { Estéticos } \\
\text { Religiosos } \\
\text { Éticos } \\
\text { Sociales }\end{array}$ & $\begin{array}{l}\text { Políticos } \\
\text { Vitales } \\
\text { Morales } \\
\text { Estéticos } \\
\text { Religiosos } \\
\text { Culturales }\end{array}$ & $\begin{array}{l}\text { Individu- } \\
\text { ales } \\
\text { Técnicos } \\
\\
\text { Trascen- } \\
\text { dentales } \\
\text { Sociales }\end{array}$ & $\begin{array}{l}\text { Útiles } \\
\text { Vitales } \\
\text { Morales } \\
\text { Estéticos } \\
\\
\text { Intelectuales } \\
\text { Trascendentes } \\
\text { Sociales }\end{array}$ & $\begin{array}{l}\text { Responsabi- } \\
\text { lidad } \\
\text { Libertad } \\
\text { Amor } \\
\text { Verdad } \\
\text { Bien } \\
\text { Belleza } \\
\text { Persona }\end{array}$ \\
\hline
\end{tabular}

Fuente: López (2005) Adaptado

De alguna manera todos esos valores son nuestros, pero tampoco son nuestros, resultan ambivalente en una circunstancia específica. Esto ocurre porque el ser humano es el que valora o el que percibe el valor que se manifiesta en el exterior, por ende el ser humano es cambiante. Excepto Otero, que manifiesta valores relativamente específicos, los otros muestran subcategoría que a su vez desarrollan valores al interior de cada uno. Por ejemplo véase la siguiente tabla 
Cuadro 3. Clasificación de los valores

\begin{tabular}{ll}
\hline \multicolumn{1}{c}{ Tipos de valores } & \multicolumn{1}{c}{ Valor } \\
\hline Sensibles & Placer, alegría \\
Útiles & Capacidad, eficacia \\
Vitales & Salud, fortaleza \\
Estéticos & Belleza, Elegancia, armonía \\
Intelectuales & Verdad, conocimiento \\
Religiosos & Sagrado \\
Morales & Amor, responsabilidad, justicia, libertad, \\
& igualdad, honestidad, solidaridad, respe- \\
& to y tolerancia \\
\hline
\end{tabular}

Fuente: Rodríguez (2008)

También porque los valores son cambiantes, el cambio es inherente a los valores, puestos que estos no son principios, si bien es cierto que muchos derivan de los principios. Como dice Covey (2003), los principios son como el territorio y los mapas como los valores. El territorio está ahí, pero los mapas sufren ajustes, y es ideal que ambos converjan o empaten. En tanto los valores son cambiantes y esto hace de su existencia una constelación, que si no se reduce hasta lo elemental se sufriría una variabilidad patológica y autodestructiva.

\section{Dominio de la subjetividad en la determinación de valores}

También puede apreciarse los valores desde la perspectiva del sujeto y el objeto, esto es desde la subjetividad y la objetividad. El primero son valores psicológicos y subyacentes al sujeto; el segundo valores derivados de la realidad adyacente, de allí que es necesario "dirimir entre la objetividad o la subjetividad de los valores, es decir, si los valores existen por sí y para sí, independiente de los sujetos o dependen de quienes asignan el valor, de sus intereses o emociones" (Rodríguez, 2008). La tabla siguiente presenta estas diferencias. 
Cuadro 4. Los valores

\begin{tabular}{|c|c|}
\hline Subjetivismo & Objetivismo \\
\hline $\begin{array}{l}\text { El valor debe su existencia, sentido y } \\
\text { validez a reacciones filosóficas o psi- } \\
\text { cológicas del sujeto que valora } \\
\text { - La discrepancia alcanza a los valores } \\
\text { mismos } \\
\text { Valoramos lo deseamos, lo que nos } \\
\text { agrada. } \\
\text { Los valores no existen en sí y para sí, } \\
\text { sino que son meras creaciones de la } \\
\text { mente, existen solamente para mí. }\end{array}$ & $\begin{array}{l}\text { - El valor existe independientemente } \\
\text { de un sujeto o de una conciencia } \\
\text { valorativa. } \\
\text { - La discrepancia se refiere a los bie- } \\
\text { nes, no a los valores } \\
\text { - Valoramos también lo que nos des- } \\
\text { agrada } \\
\text { - Los valores son absolutos, existen } \\
\text { en sí y no para mí }\end{array}$ \\
\hline
\end{tabular}

Fuente: Frondizi, 2001

Sin embargo es casi imposible separar el sujeto del objeto, de su permanente interacción la filosofía encuentra motivos para la reflexión profunda. El sujeto, es dominado por su subjetividad y por más objetivo que se pretenda ser, siempre el sujeto está contaminado por sus características particulares y peculiares. Todo juicio e interpretación está cargado en más o menos de subjetividad. Después de todo el sujeto es objeto animado y el objeto es sujeto inanimado, porque el ser humano también es objeto de estudio en la antropología.

Aunque objeto y sujeto son dos dimensiones aprehensibles el uno por el otro, no "permanecen eternamente separados", como afirma Hessen (2007: $38)$, por la misma razón que en la muerte el sujeto es un objeto perfecto. La mente analítica puede separar en partes un todo y confundir la parte como un todo en su proceso de síntesis. El sujeto y el objeto son inseparables, uno sin el otro no existe y por tanto el conocimiento sería nulo como también los valores serían vacíos.

El objeto y el sujeto reviven sus roles categóricos en el enfrentamiento entre la modernidad versus la posmodernidad, el primero objetivo y el segundo subjetivo; el primero centrado en la naturaleza y lo que esta puede proveer para el desarrollo humano, el segundo centrado en el hombre y lo que este puede hacer por sí mismo y por los demás. Ambos estadios históricos también son filosóficos y fuente de valores, que se presentan como antípoda del otro. 
Cuadro 5. Fuente de valores

\begin{tabular}{ll}
\hline \multicolumn{1}{c}{ Modernidad } & \multicolumn{1}{c}{ Posmodernidad } \\
\hline 1. Lo holístico & 1. Lo fragmentario \\
2. Lo absoluto & 2. Lo relativo \\
3. La unidad & 3. La diversidad \\
4. El gran relato & 4. El pequeño relato \\
5. Lo universal & 5. Lo particular \\
6. El estado & 6. La ciudad, la región, el país \\
7. Lo objetivo & 7. Lo subjetivo \\
8. El esfuerzo & 8. El placer \\
9. El pasado/el futuro & 9. El presente \\
10. La razón & 10. La emoción \\
11. La certeza & 11. La duda \\
12. La autorresponsabilidad & 12. La responsabilidad diferida \\
13. Secularización frente a la religión & 13. Espiritualidad frente a la religión \\
14. El día & 14. La noche \\
15. El trabajo & 15. La fiesta \\
16. La utopía & 16. La quimera \\
17. La construcción & 17. La deconstrucción \\
18. La familia frente a la comuna & 18. La familia frente a la pareja \\
19. Lo masculino & 19. Lo femenino \\
20. Lo leído/lo hablado & 20. Lo visto \\
21. El papel & 21. La pantalla \\
22. El clan & 22. La red (red de guetos a veces) \\
\hline
\end{tabular}

Fuente: J. Elzo (2004)

Como puede notarse, la modernidad se caracteriza por lo constante, lo continuo, lo fijo quien sabe porque su objeto de estudio era la naturaleza y al ser descubierta muchas de sus leyes proyectaron a la vida social su decurso inexorable, y por tanto cupieron los metarrelatos (conceptualización posmodernista) como paradigmas totalizadores que despertaron adhesiones místicas de multitudes, siguiendo premunidos de fe y esperanza en la conquista del reino soñado.

Esta modernidad, que Fontenelle (1657-1757) puso en contraste con la antigüedad, aseguró a la humanidad el mito del desarrollo y progreso infinito, acicateado por la concepción lineal del tiempo y no había razón para dudar aun cuando Descartes (1596-1690) invitaba a la duda. La duda cartesiana, quedó arrinconada a los antros de la reflexión filosófica y de la ciencia, pero no se vulgarizó al andante común, quienes son los verdaderos protagonistas prácticos del cambio aunque visceral y carente de juicio. 
Esto fortaleció el mito del progreso indefinido y acorde con eso los valores tomaron el color de la época, valores firmes y fuertes, únicos vehículos que asegurarían el futuro, dado las lecciones del pasado. Lo racional y objetivo, en donde el sujeto observa y define las cosas en función del objeto sin dejarse influenciar, dicta valores distantes del sujeto o en todo caso, no provenientes del sujeto, pues él los encuentra, los descubre y los acepta. Es Kant (1724-1804) con su categoría del deber ser, el que catapulta las vivencias de la época en la experiencia filosófica, "Obra de tal manera que uses la humanidad, tanto en tu persona como en la persona de cualquier otro, siempre como un fin y nunca como un medio". Esto es una ética de los máximos, el ser humano debe ser y debe hacer "Obra sólo según una máxima tal que puedas querer al mismo tiempo que se torne en ley universal".

"Obra como si la máxima de acción hubiera de convertirse por tu voluntad en ley universal de la naturaleza".

Esta objetividad en el examen racional, llamado positivismo por Comte (1798-1857), pues todo es engaño o ilusión a menos que sea observable y probado en la naturaleza o el laboratorio, constituye el espíritu de la modernidad imponente y grandilocuente. Sin embargo, nada perdura en este mundo donde la homeostasis erupciona al más leve cambio emocional entrópico.

Es así que sus mensajes de progreso indefinido y pretensiones de solución científica a todos los enigmas humanos se ven sepultadas por el repentino tronar de bombas y cañones de la primera y segunda guerra mundial, las decepcionantes y traumáticas experiencias de Corea y Vietnam. El repentino enfrentamiento a la muerte sin sentido, quitó toda ilusión de los años de prosperidad que ofrecía la modernidad. La desilusión, dio paso a la posmodernidad, en donde todo se vuelve efímero e inmediato.

La posmodernidad acaba con la idea de progreso indefinido, el sujeto ya no es un estable sustento de valores firmes, más bien estos se erosionan en una multitud infinita de valores light sin fundamentos y el sujeto se confunde en su vacío existencial, la historia no tiene sentido menos el futuro, solo tiene valor el presente. Si Dios ha muerto, como dijeron Hegel (1770-1831); Dostoyevski (18811881) y (Nietzsche, 1844-1900);) todo vale: "Si Dios no existe nada es inmoral. Todo es lícito, incluso el crimen" (Ivan Karamazov, 2011), la modernidad con su calificaciones de bueno y malo, resultaba vergonzante por parecer maniquea, en la posmodernidad desaparece todo lo que parezca maniqueo, resultando un caldo de cultivo perfecto para el metarrelato hindú, del yin-yan.

El proverbial: "comamos y bebamos que mañana moriremos" (1 Cor. 15:32), asume características nihilistas, en la mente postmoderna, el cuadro 
anterior al listarse los valores de la postmodernidad frente a los valores de la modernidad permitirá comprender la pérdida de horizontes de los que sabiéndolo o no, caen en la descripción de posmoderno. Es angustiante para la mente racional, pero resulta atractivo para quien vive y experimenta el predominio del corto plazo o por la visión cuya frontera son las narices.

La posmodernidad se caracteriza por la subjetividad, en oposición de la objetividad moderna. La subjetividad encuentra su expresión en las percepciones, argumentos y lenguaje desde la mirada particular del sujeto, esta perspectiva supone que cada quien es un mundo y cada quien puede valorar su pre-juicio particular, y nadie puede oponérsele, porque si él lo piensa, también eso es verdad. Por ejemplo, bajo el dominio de la objetividad el texto se interpreta por las circunstancias que rodean al autor, pero la subjetividad avala que "más importante es lo que el lector comprende que lo que el autor quiso decir" (Land, 1996; Westphal, 2003) El racionalista es objetivo y en la moral es un estoico con tendencia al ascetismo. El deber ser de Kant, aspira un logro mayor en la conducta, con todos los sacrificios que ello requiere, importa la opinión de los demás y donde "la mujer del César no solo debe ser honesta sino parecerlo". Fraterno con lo absoluto, no es difícil aceptar la heteronomía de la ética y los valores, estos no emergen del individuo, sino que vienen del exterior, de Dios mismo y por tanto había que cumplirlo.

La modernidad racionalista, tenía a Dios como el modelo de perfección, y nada mejor para liquidarla que matando a Dios, inaugurando la otra época, el dominio de la subjetividad. El posmoderno es subjetivo, y en la moral es un epicúreo, con tendencias al hedonismo, la búsqueda mayor del placer sensorial e inmediato, donde la existencia tiene como razón la búsqueda del placer y en donde el cuerpo es un aliado.

El hedonismo llevado a la ciencia, se corporiza en el utilitarismo inglés de Jeremy Bethan (1748-1832) y Stuart Mill (1806-1873), quienes elevan el bien y el placer al nivel de lo útil para la sociedad, en la filosofía el utilitarismo y el pragmatismo se asocian, y en la moral tiene sus aporías en tanto el bien es tal en la medida de su utilidad: "mi amigo es tal, en tanto me sea útil".

El marxismo siendo asceta y pareciendo estoico, no lo fue, sus lucha fueron en tanto querían el mayor placer para las mayorías, las clases no privilegiadas y sus intelectuales acuñaron la frase "los bienes no son del que lo posee, sino del que lo necesita", así desarrollaron la lucha de clases: "El poder nace del fusil" (Mao Tse-Tung). La revolución estaba atada a la necesidad y la necesidad es más nítida cuando se busca el placer, y el placer no tiene ataduras, siempre busca salir con la suya.

Revista Apunt. Univ. VOLUMEN VI • NÚMERO 2 p. 125 - 145 
El placer y la subjetividad, son aliados, y la posmodernidad es un caldo de cultivo para desarrollar con mayor profundidad y extensión el hedonismo. En esta época es el individuo el que importa y el que impone, y por tanto los valores fuertes se diluyen, por cuanto el individuo no tiene mayor responsabilidad que consigo mismo. El capitalismo, muy bien avisado de estos cambios de visión, ha sabido aprovechar la nueva estructura líquida y ha extendido sus tentáculos con mayor certeza acumulando excesiva riqueza a merced de los incautos que solo buscan la satisfacción personal guste o no le guste al grupo.

El consumismo es una materialización posmoderna, importa comprar aunque no se sabe para qué, y parezca una necesidad, esta necesidad es creada por las "mass media" y como el juicio de ser nuevo no tiene hitos referenciales, caen en las redes de la ilusión falsa creada por el séptimo arte con todos sus juegos de luces y colores. El sujeto posmoderno, es esclavo de su propia subjetividad, llamémoslo de su propia opinión, al haber muerto las referencias y venido a menos el principio de autoridad. Ahora la autoridad son todos, nacidos de la igualdad.

La igualdad, siempre fue buscada y no se puede acantonar en una etapa histórica; sin embargo, parece asumir ribetes apocalípticos en la presente época del dominio de la subjetividad. Lo que se desea y se piensa, eso es bueno y si no es legal hay que legalizarlo, las minorías tienen tribuna y las mayorías las apoyan más por la compasión que por la razón, haciendo de muchas minorías una fuerza descomunal que pone en riesgo al poder constituido. Los pocos de la mayoría que quieren manifestar su posición definida termina adjetivados de locura o esquizofrenia, como ocurrió con miss California 2009, Carrie Prejean, por opinar que el matrimonio debe ser entre hombre y mujer, se prendió un escándalo de proporciones dantescas que le costó la corona y despertó un debate desproporcionado con el género de concurso.

En el dominio de la subjetividad, cada quien tiene su verdad, y es signo de intolerancia si alguien quiere mostrar una verdad general. Es una dictadura no percibida, pero es y reina. Es un paradigma o una cosmovisión, vivida y actuada por todos los seres humanos, sin requerimiento de tener conciencia de su alineamiento. Es un modo de pensar y vivir sin darse cuenta. El hombre subjetivo, vive solitario y con sus propios placeres, colectiviza la reunión pero no la experiencia, prueba de ellos es la familia a la mesa, todos textean y nadie conversa, cada quien tiene su interés, que nos es de los demás. Su vitalidad esta anexada el celular y a un like. 


\section{La tolerancia es intolerancia}

Este estado posmoderno o paradigma posmoderno, desestructuraliza el pensamiento social y reestructuraliza el pensamiento individual, de tal modo que la mayoría vive creyéndose una unidad y no parte, en el todo ¿Son los signos de los tiempos? El individualismo se enerva y encuentra su ideología básica que sustenta sus mecanismos de acción y justifica sus procederes basados en que "yo soy yo no mi circunstancia" y lo social tiene sentido en tanto respete la individualidad para encarnar el bien subjetivo de los mínimos morales, de la ética civil y ciudadana donde cada quien no está obligado a nada si es que no quiere y puede hacer todo lo que le place con tal de no invadir el espacio ajeno.

Esto deriva en una opresión extraña, pero cierta, opresión extraña porque pocos se da cuenta de estar oprimidos y aún más, la mayoría es cómplice de su propia esclavitud, dado la búsqueda obsesiva de una imagen hipócrita, exaltando la apariencia, las formas sobre la esencia. La espada de la posmodernidad para someter la ilusión vaporosa y deseada, es la tolerancia, el eslabón para unir lo esencialmente diferente y para proscribir a los que advierten del peligro.

La tolerancia es un evaluador, una medida, más que un concepto de belleza heroica y digna de toda hazaña, es un instrumento de opresión de la posmodernidad. La ex miss California Prejean (2009) como ya se dijo, opinó a favor del matrimonio heterosexual. Escribió Pablo Ccarpellini, periodista, desde Los Ángeles en El Mundo de España (2009) refiriéndose al bloguero de tendencia gay y jurado calificador: 'El propio Pérez la mandó al carajo minutos después de que terminase el concurso. "Dio la peor respuesta de la historia en un concurso de belleza. Perdió porque es una puta tonta", dijo sin pelos en la lengua'. A entendedor inteligente, el que no es tolerante sufre la furia de la intolerancia.

La tolerancia como valor posmoderno ha relativizado los valores individuales y los valores firmes no deben ir más allá de los consensos, todos bajan al nivel del grupo. El grupo ha sido útil para sinergizar el resultado y el cálculo, pero muy dudoso en mejorar la moral, que al requerir sacrificios no va en consonancia con los placeres de la época, la búsqueda de la máxima felicidad, recurriendo al imperio de los sentidos más que de las responsabilidades, porque este último "crea traumas personales y sociales".

Por tanto, tolerancia e intolerancia en un escenario dirimente, resultan sinónimos, no se da la una sin la otra. Lo paradójico es la fortaleza de la intolerancia que somete a los sujetos a ser tolerantes, en caso opuesto resurge la inquisición proveniente de nuevas minorías, que con su grito espantan a los sensatos hasta 
callarlos o hacerlos cómplices. Con visos de sospecha se observa el clamor de los pocos que tumban gobiernos e imponen leyes, apañado en el silencio y la indiferencia de los muchos. "Lo que me preocupa no es el grito de los malos, sino el silencio de los buenos" (Luther King).

La tolerancia ha tornado las herejías de ayer en virtudes de hoy y las virtudes de ayer en herejías de hoy, como una inversión de valores ante el lamento de todos y la inoperancia de los mismos, carentes de acciones que regulen un esfuerzo por evitar que la civilización se deslice entre los dedos como el agua.

La modernidad aun sostiene los fundamentos de la civilización, porque una civilización se sostiene con fortaleza en sus instituciones tutelares, como absolutos que fijan hitos y fronteras con aquellos que la amenaza, pero la posmodernidad está licuando los límites e intentando hacer polvo de sus fronteras, tarde o temprano estos titanes tendrán que enfrentarse en una decisiva batalla entre el primero que se resiste morir y el segundo que se esfuerza por emerger. En tanto, la desilusión emerge fuerte y decidido a acabar con todo lo que signifique prohibición tutelar, ganando la adhesión de las mayorías no tanto por su razón lógica o sistémica, sino por la compasión de las masas, que apoyan más por solidaridad que por la justicia de su causa.

\section{Los valores, razón de ser de la comunidad}

¿Y por qué todo esto? Es el dominio del sujeto, antro generador de la subjetividad. Una verdad, que era para todos igual en la modernidad, ahora es una verdad fraccionada según la valoración de cada individuo. Ahora Machado2 diría "tu verdad o mi verdad, pero no la verdad". Los uniformizadores, siempre han sido elementos de comunión, han sido faros guiadores igual para todos, tiene sus defectos y algunos demasiado peligrosos para la justicia y la equidad, pero han sido y aun son el elemento aglutinador de los esfuerzos humanos del grupo o nación, es el elemento de cohesión y solo así una empresa o nación puede consolidarse en el consenso de los negocios y de la política internacional. El asesino, sencillamente era asesino para todos porque quitó la vida injustamente a un inocente. Pero, como ahora, cada quien tiene su verdad, para uno es un asesino, para otros un justiciero, para un tercero un guerrillero, para otros un revolucionario, para otros un político y para otros un héroe o un mártir.

¿Puede construirse civilización con tamaña confusión? ¿Nos amenaza una deconstrucción de civilización? Por su parte, la psicología también pone su 
aporte con su calificación de "trauma" una categoría metafísica reconocida por sus resultados nihilistas, de ese modo, la autoridad de los viejos ha sido reemplaza por la autoridad de los imberbes, el tradicional jefe de familia ha estallado en un millos de alternativas en manos de los más jóvenes y el concepto de educación en multitud de conceptos. El castigo redentivo, ha sido calificado de violencia y la violencia de los hijos como justa defensa y en la relación estado-pueblo, como derecho a la insurgencia. El reo ya no es un preso, sino un privado de libertad, porque si le dice preso, puede generársele "traumas irreversibles" ¿Hasta dónde se puede construir civilización con una babilonia de verdades y encontrar armonía con multitud de propuestas irreconciliables? Ya no se sabe si el héroe es un mártir o un sonso que no escapó a tiempo; si el aborto es un crimen o un derecho a la salud mental de la gestante.

Tener un código para cada persona y que un crimen sea juzgado de acuerdo a si es Abel, Caín, Seth y mil millones de nombres en su circunstancia particular se caerá en un imposible y los códigos no cabrían en el mundo. Entonces si esto es un imposible ¿cuál es el reino de la posmodernidad, puesto que es incapaz de dar respuestas jurídicas a todos los casos de forma individualizada? Claro es que la posmodernidad no encuentra aplicación en todos los ámbitos de la vida, sino esencialmente en la moral y de allí deriva los aspectos encarnacionales en la sociedad, en la economía, en la política y en la tecnología.

La posmodernidad no es nuevo, pero si es más complejo que sus símiles del pasado, está asociado al fin de las civilizaciones y el eclipse de la moral y sus valores más representativos. También está asociado a la "muerte de Dios" o "muerte de los dioses". Dios o los dioses, encarnaron el ideal de perfección de un pueblo, era el símbolo de su unidad y la esencia de sus valores.

La revolución francesa, no hubiera existido si primero no mataban a sus dioses que tenía al pueblo sujeto a su rey, símbolo de un absolutismo divino. Los reyes en Francia, llegaron a su fin envueltos en escandalosas experiencias de los sentidos, subjejtividades que solo ellos valoraban dando espalda al pueblo. Los valores de los reyes se licuaron en sus placeres cortesanos y valores caducos. Cayeron, porque ya no representaban la firmeza de los valores de los padres fundadores.

El pueblo, para lavantarse contra su rey, tuvieron que amputar de su mente la imagen de su dios y es por eso que tuvieron el valor de guillotinar a Lui XVI, símbolo de su divinidad porque se sintieron libres para actuar y de allí emergieron tres nuevos valores que signaron la vida de las naciones hacia no sabemos cuándo dure este ciclo republicano: Libertad, igualdad y fraternidad. A la muerte de dios por el hombre le siguió la muerte del hombre por Dios. El 
nuevo dios de la época, era republicano y demócrata, claro que estamos en el reino de la modernidad y la postmodernidad es su fin último, no es otra etapa, sino solo la caducidad de la civilización.

Desde la revolución francesa hasta nuestros días han pasado 227 años (2016-1789) ¿tiempo suficiente para un cambio de valores globales, dado un sistema caduco representado por la desilusión? El imperio neo Babilónico duro 66 años (605-539 a.C), a su último rey le importó más su orgía, glotonería y embriaguez que proteger el imperio, los valores fundacionales acabaron en el basurero reemplazado por subjetividades de los sentidos.

El Imperio Medo Persa, duró 208 años (539-331 a.C) al fin de su periodo imperial, así escribe un autor de Jerjes, el fracasado rey de las Termópilas y de las guerras médicas: "este era un joven apuesto, de carácter alegre, que sentía más afición a la molicie y a los placeres que a las empresas bélicas" y en otra descripción "Jerjes mismo iba en el centro de sus huestes, acompañado de un numeroso séquito de criados y cortesanos, y rodeado de todas las comodidades y el lujo que las más fabulosas riqueza podían proporcionar a un soberado iQué diferencia con los días de sus Dobres, vigorosos y afortunados progenitores! (Tesoro de la Juventud). El debilitamiento del reino, más las luchas intestinas de los sucesores al trono, finalmente acabaron con los Medo-Persas, el año 331 en la batalla de Arbelas, dando inicio a otro imperio con sus propios valores.

El imperio griego, duró 163 años (331-168 a. C) Apenas 12 años de fundado se divide territorialmente incapaz de mantener la unidad del imperio, seguido de luchas intestinas que van debilitándolo hasta que finalmente, se impone cae, si bien intelectualmente supervive invencible hasta nuestros días.

El imperio romano, duró 644 años (168 a. C-476 d. C) su larga vitalidad se debe a su reinvención constante ante los deterioros cíclicos que surgía, pasó por los periodos conocidos como Roma antigua, Roma Republicana y finalmente Roma Imperial (27 a. C - 476 d.C.) Pero igual, terminó enlodado en sus propias desvalorizaciones de las virtudes que fomentaron los padres fundadores del imperio, hay otras causas también de la caída del imperio, pero solo eran la materialización de la moral en decadencia. Los valores de Marco Aurelio: Sabiduría, justicia, fortaleza y temperancia, se cambiaron por pan y circo (El Gladiador, 2000).

El imperio inca era fuerte mientras era indiscutible la existencia de un solo heredero al trono, el hijo del sol. Pero cuando esa verdad global, se fraccionó en dos bandos y el sol puede también tener dos herederos y cada quien no pecaba sin aceptaba a uno u otro, entonces llegó el fin, la unidad se fraccionó y la verdad del único hijo del sol se partió, y con ella el imperio feneció. 
Tales ejemplos de la historia, señalan que la posmodernidad no es una etapa alterna a la modernidad, ni opuesta, sino solo su cola dando el último coletazo, si no ocurre nada estupendo que refresque su experiencia, una crisis desproporcional se avecina sobre la humanidad que se deleita en la pluralidad moral y permitiendo que cada quien haga lo suyo a condición de no afectar a otros. Pero el punto es que si afecta, y el mundo no está preparado para entenderlo. La tolerancia ha hecho su trabajo y ha silenciado las voces que se oponen a este camino que lleva "como vacas al matadero"

\section{Los valores empresariales requieren vínculos fuertes}

Si la cultura actual ha aceptado el cortos relatos, la fuerza individual para vivir su propia historia sin sujetarlo a otra general, si cada quien puede darle a la vida una interpretación subjetiva y darle expresión a sus cuerpos sin restricciones ni prohibiciones, en el cual la ley para cada uno es una aspiración permanente, existen elementos para creer que esto es solo una rebelión de la desadaptación y no una nueva alternativa mejorada para la existencia de la raza humana. El estallido de los valores en un sinfín de pequeños valores fenoménicos, no se sostiene al ver instituciones firmes que no son alteradas por la simple ideología de que no hay ley superior a la voluntad del individuo.

Lo único que ha logrado la posmodernidad, si logro se puede llamar es la monumental acumulación de riqueza por los pocos que supieron ver en la desadaptación el vació que debían llenar con productos duros y blandos, que al fin de cuentas no produjo la felicidad deseada por los sedientos de placer.

El nuevo capitalismo ha aprovechado con excelente resultados la condición posmoderna, y no ha mezquinado "los buenos sueldos" a sus trabajadores y ejecutivos, con la seguridad de que el dinero otorgado retornará en el consumo exorbitado de los grandes asalariados. Los valores posmodernos, nos confronta con la difuminación, y la dilución en la dimensión moral, porque si bien es posible sostener valores tanto como individuos existen sobre el globo, en lo moral sino se tienen un elemento de unidad y fortaleza, es posible echar al traste todos los programas políticos de buen gobierno y los programas familiares de buena educación.

Pueden haber 500 formas de hacer las compras y aún más, pero 500 formas de conceptuar el término familia, nos enfrenta al eclipse de la educación familiar, por el hecho mismo de que se justifica entender 500 formas de conceptuar el constructo "padres". La empresa misma eclipsaría sus estrategias si se deja a cada individuo expresar su conducta ética como bien le pareciera, y la palabra 
corrupción, robo, soborno y fraude, tendría mil formas de conceptualización justificada y nadie podría sancionarlo si sencillamente se tratara de tolerar a cada quien expresar su subjetividad de manera tan monstruosa.

Y sin embargo, la empresa no está segura si los valores morales del hogar se destruyen en un millón de pequeños cristales. Por eso los manuales, las normas internas de control y otros, tienen por función de que todos se atengan a una meta, una misión, una visión y nadie está permitido a pensar como quiera o como le dicte su conciencia privada. Esto es una señal fuerte de que la moral no puede también diluirse en un millón de conductas justificada porque sencillamente representa la libre expresión de cada quien aunque esto suene desafinado una cultura natural.

De allí que la moral debe descubrir los elementos comunes que fortalecen a una civilización y no describir permisivamente las diferentes expresiones y justificarlas porque sencillamente es derecho de la persona a su libertad. Si la empresa permitiría eso, se cae y ¿por qué la moral lo permitiría?

Esta condición posmoderna da la sensación de desorientación, y tiene que ver mucho con las concepciones paradigmáticas de la sociedad. La libertad irrestricta justifica todo, pero no todo tiene justificación, pero esta libertad irrestricta para que tenga fuerza es necesario matar primero todo aquello que suena a represión y esa represión como se dijo antes es el concepto de Dios, que prohíbe hacer determinadas cosas, una vez muerto esa idea, entonces todo es posible.

Y para tener valores firmes y fuertes que construyan la civilización y detengan esta marea de mundanismo, es necesario retornar a Dios, símbolo de unidad y fuerza y no de dispersión y debilidad. Otra alternativa nos confronta con la destrucción cultural esencia y fortaleza de la civilización, y también expresión de la conducta empresarial exitosa. 


\section{Los valores como resultado de la relación Dios-hombre}

\section{Referencias}

Agustín de Hipona. (1977). La ciudad de Dios. Madrid: Biblioteca de Autores Cristianos. T. I. Obras de San Agustín XVI.

Bartolomé, Ferreriros, Fondevilla y Morilla (1979) Educación y valores. Madrid. Instituto de Estudios Pedagógicos Somosagua, pág, 23, 24.

Dostoyesvky, F. (1998). Los hermanos Kamarazov. Madrid. Editorial Luarna

Elzo, J. (2004). “La educación del futuro y los valores”. En: Debates de educación (2004: Barcelona) [artículo en línea]. Fundación Jaume Bofill; UOC. [Fecha de consulta: 31/07/16]. http:// www.uoc.edu/dt/esp/elzo0704.pdf

Frondizi, R. (2001). ¿Qué son los valores? Introducción a la axiología. decimoséptima reimpresión. México: Fondo De Cultura Económica.

Gladiador. (2000). [film] Hollywood: Mel Gibson. Universal Picture-Dream Works pictures SKG.

Hegel (1990). Fenomenología del espíritu. Madrid. Revisa de Occidente, textos filosóficos

Heidegger, M. (2000). Kant y el problema de la metafísica, México. Fondo de cultura económica.

Hessen, J. (2007). Teoría del conocimiento. México. Grupo editorial Tomo SA de CV

Land, G. (1996). The Challenge of Post-modernism. Miami. USA. Rev. Dialogue 8.1, pp. 5-8. pdf.

López de Llergo, A. (2005). Valores, valorizaciones y virtudes. México. CESCA

Diario el Mundo. (2009). Miss California contra el matrimonio gay. Recuperado, 08 de febrero 2016. Disponible en: www.elmundo.es/elmundo/2009/04/26/cronicasdesdeeeuu/1240743272. html

Nietzsche, F. (2002). La gaya ciencia. España. EDAF. Sección 125

Putin, V. (2016) Europa se está muriendo. Recuperado 06/02/2016. Disponible en: http://elcomercio. $\mathrm{pe} / \mathrm{mundo} /$ actualidad/putin-europeos-se-estan-muriendo-matrimonios-gay-noproducen-ninos-noticia-1633442.

Rodríguez, M. (2008). Formación gerencial en valores. Colombia. Facultad de Ingeniería y Arquitectura, Universidad Nacional de Colombia, sede Manizales

Rokeach, M. (1973). The nature of human values. N.Y. Free Press

Covey, S. (2003). Los 7 hábitos de la gente altamente efectiva. Bs.As. Editorial Paidos, 2 da reimpresión.

Tesoro de la Juventud. El encubrimiento y caída de Persia. Biblioteca virtual, disponible en: http:// www.biblioteca.org.ar/libros/6296.pdf

Westphal, M. (2003). Blind Spots: Christianity and Postmodern Philosophy. Christian Century. June (2003):32-35, Ebscohost. Recuperado: 15 sept. 2013. Disponible en: http://www. christiancentury.org/article/2003-06/blind-spots 